\title{
Bioactive Components of Leafy Vegetable Edible Amaranth (Amaranthus mangostanus L.) as Affected by Home Cooking Manners
}

\author{
Sudan Han, Baojun $\mathrm{Xu}^{*}$ \\ Food Science and Technology Program, Beijing Normal University-Hong Kong Baptist University United International College, \\ Zhuhai, Guangdong, China \\ *Corresponding author: baojunxu@uic.edu.hk
}

Received July 21, 2014; Revised August 04, 2014; Accepted August 08, 2014

\begin{abstract}
The objective of the current study is to investigate how home cooking, a common way for many societies to prepare vegetables before consumption, affect bioactive components and antioxidant capacities of a commonly consumed leafy vegetable edible amaranth. The amaranth was cooked by simmering, boiling, frying, blanching and steaming. The contents of total phenolics, anthocyanins, $L$-ascorbic acid, carotenoids, lutein, beta carotene and ferric reducing antioxidant power (FRAP) of edible amaranth were determined after the cooking by colorimetric assays. Home cooking proved to degrade anthocyanins but increased carotenoids. Steaming increased total phenol content (TPC) about 50\% while simmering reduced 31.1\% of TPC. Simmering, frying and blanching deduced $L$-ascorbic acid content by $18.6 \%, 17.2 \%$, and $14.0 \%$, respectively. Steaming increased $L$-ascorbic acid by $21.7 \%$. Both lutein and beta-carotene content was reduced by frying but increased by other methods. FRAP values of cooked vegetable were higher than the raw counterpart, which indicated the cooking increased the antioxidant capacities of the edible amaranth.
\end{abstract}

Keywords: amaranth home cooking, vegetable antioxidants, amaranth carotenoids, amaranth phenolics

Cite This Article: Sudan Han, and Baojun Xu, "Bioactive Components of Leafy Vegetable Edible Amaranth (Amaranthus mangostanus L.) as Affected by Home Cooking Manners.” American Journal of Food Science and Technology, vol. 2, no. 4 (2014): 122-127. doi: 10.12691/ajfst-2-4-3.

\section{Introduction}

It is widely accepted that vegetables play important roles in preventing the development of the cardiovascular diseases, aging-related diseases, obesity, cancers and improving human's memory (Wayne et al., 2000). The health promoting effects of vegetables is attributed to their natural dietary antioxidants. Dietary antioxidants prevent free radicals relative to aging such as reactive oxygen species in the human body (Nilsson et al., 2004). The free radical theory of aging involves cumulative damage as the of the natural free radical oxidative changes, which over time results in increasing antigenicity, protein changes, and oxidative DNA damages (Edelstein et al., 2009). Vitamin $C$ is a powerful antioxidant contributing to normal function of the immune system (Melvin et al., 2010). Polyphenolic compounds have most antioxidant function acting as electron donors, electron acceptors, decomposer of peroxide and hydroperoxides, metal activators and deactivators and UV absorber (Svobadva et al., 2003). Anthocyanin is demonstrated powerful antioxidant properties against low- density lipoprotein oxidation to reduce the risk of the coronary heart disease (Wallace, 2011). The carotenoids are yellow to red pigment with major dietary representatives $\alpha$-carotene, $\beta$ - carotene, lutein, cryptoxanthin, zeaxanthin and lycopene. The carotenoids are scavengers of reactive oxygen species (ROS) formed in physiological processes. ROS are able to damage biologically relevant molecules such as DNA, protein, lipids and carbohydrates (Kumpulainen et al., 1999).

Amaranth (Amaranthus mangostanus L.), commonly called 'Xiancai' in Chinese, is an annual herb in the family of Amaranthaceae. As a kind of vegetables, Amaranth is ranked as one of top five vegetables in antioxidant capacities (Walter et al., 2001). It contains plenty of bioactive components, such as $L$-ascorbic acid, beta-carotene, polyphenol, anthocyanins, lutein (Walter et al., 2001). It has been used as an antipyretic to reduce labor pain in Indian and Nepalese traditional medicine (Kirtikar et al., 1987). As astringent, diuretic, haemorrhage and hepatoprotective agent, amaranth has also been used to treat bladder distress, piles, tooth-ache, blood disorders and dysentery (Madhav et al., 2008). Amaranth has been evaluated for in vivo anthelmintic, anti-inflammatory and antioxidant properties (Lakshmanb et al., 2012).

Most vegetables including amaranth go through cooking such as frying, simmering, boiling, steaming, and blanching before consumption. Cooking has a significant effect on chemical compositions such as bioactive components, antioxidant activities and physical 
characteristics in terms of color, texture and flavor. However, the effect can be either positive or negative depending on the process methods, vegetable species and shapes (Bernhardt et al., 2006). Amaranth is one of commonly consumed leafy vegetables in Guangdong Province, China. The vegetables are consumed after home cooking procedures such as simmering, frying, boiling, steaming, and blanching. Nevertheless, knowledge about its bioactive components, for instance, ascorbic acid, polyphenol, anthocyanins, carotenoids and antioxidant activities is limited. It is not clear how home cooking affects these bioactive components and their antioxidant capacities. Therefore, the current study aims to investigate the contents of polyphenol, anthocyanins, ascorbic acid, carotenoids and antioxidant activities in terms of FRAP as affected by home cooking manners including simmering, frying, boiling, steaming and blanching.

\section{Material and Method}

\subsection{Edible Amaranth}

Edible amaranth was cultivated in a local farm in Zhuhai, Guangdong Province, China. A picture of the vegetable was shown in Figure 1.

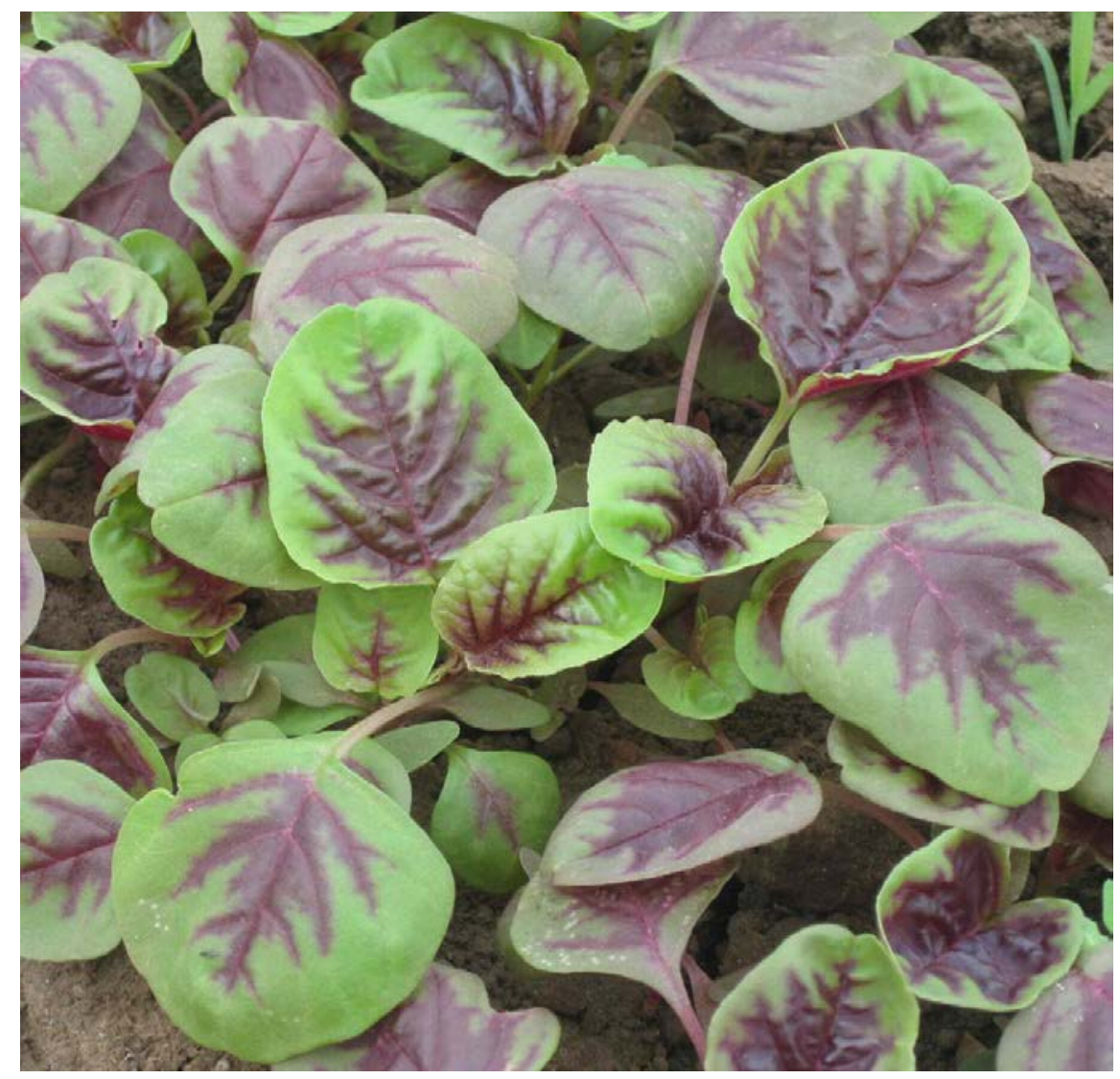

Figure 1. Picture of leafy vegetable edible amaranth

\subsection{Chemicals and Reagents}

Acetate buffer, sodium hydroxide, citric acid, potassium chloride, dimethyl sulfoxide (DMSO), methylbenzene, hexane, acetone, methanol, heptane, isopropanol and ethanol were purchased from Tianjin Damao Chemical Reagent Co., Ltd (Tianjin, China). Gallic acid and ferric chloride were supplied by Sinopharm Chemical Reagent Co., Ltd (Shanghai, China). Metaphosphoric acid and $L$-ascorbic acid were obtained from Tianjin Kermel Chemical Reagent Co., Ltd (Tianjin). Ferrous sulfate heptahydrate was provided by Luoyang Chemical Reagent Co., Ltd (Luoyang, China). 2,4,6-Tri[2pyridy-s-triazine] (TPTZ) were offered by Sigma- Aldrich Co. Ltd (St. Louis, MO, U.S.A). Folin-Ciocalteu reagent was from Shanghai Sanjie Biotechnology Co., Ltd (Shanghai, China).

\subsection{Home Cooking of Edible Amaranth}

The fresh raw amaranth was cleaned with tap water and drained with the paper towel. Three parallel portions of vegetable were sampled, and then subjected to each thermal processing in triplicate. The cooking time was selected based on the time used to obtain palatable vegetable. Briefly, for boiling treatment, $100 \mathrm{~g}$ cleaned amaranth was immersed in $1000 \mathrm{~mL}$ of boiling water for 3 min. For steaming treatment, $100 \mathrm{~g}$ cleaned amaranth was put on a steaming rack over $1000 \mathrm{~mL}$ water in a steamer covered with a lid, and steaming was conducted for 10 min. For simmering processing, 100 g cleaned amaranth was soaked into $1000 \mathrm{~mL}$ of boiling water, and then the vegetable was simmered at temperature about $94^{\circ} \mathrm{C}$ for 30 min over a slow fire. For pan-frying treatment, $100 \mathrm{~g}$ cleaned amaranth was added into the boiling corn oil at temperature around $232^{\circ} \mathrm{C}$ for $4 \mathrm{~min}$. For blanching, $100 \mathrm{~g}$ edible amaranth was immersed with $1000 \mathrm{~mL}$ boiling water for $1 \mathrm{~min}$. After cooking, water or oil was drained off from the samples. Cooked and fresh samples were homogenized by a food blender. All the crushed samples 
were freeze-dried. The dry samples were stored at $-20^{\circ} \mathrm{C}$ in a freezer for further analysis.

\subsection{Determination of Total Phenolic Content (TPC)}

The total phenolics were extracted and determined by a Folin-Ciocalteu assay using gallic acid (GA) as the standard by referring a previous publication ( $\mathrm{Xu}$ and Chang, 2007). The absorbance was measured using a UVvisible spectrophotometer (TI-1901, Beijing Purkinje General Instrument Co., Ltd, Beijing, China) at $765 \mathrm{~nm}$ against a reagent blank. The TPC was expressed as milligrams of gallic acid equivalents per gram of freezedried amaranth (mg of GAE/g).

\subsection{Determination of Monomeric Anthocyanins Content (MAC)}

The MAC was determined using a $\mathrm{pH}$ differential method (Liu et al., 2008) by measuring absorbance at 700 $\mathrm{nm}$ and $520 \mathrm{~nm}$. The pigment content was expressed as micrograms of cyanidin-3-glucoside equivalents per gram of freeze-dried amaranth, using an extinction coefficient of $26900 \mathrm{~L} \mathrm{~cm}^{-1} \mathrm{~mol}^{-1}$ and molecular weight of $449.2 \mathrm{~g}$ $\mathrm{mol}^{-1}$.

\subsection{Determination of $\boldsymbol{L}$-Ascorbic Acid}

$L$-Ascorbic acid was extracted with meta-phosphoric acid according to the latest publication (Huang et al., 2014). Briefly, $0.5 \mathrm{~g}$ of freeze-dried raw or processed amaranth was ground with $13 \mathrm{~mL}$ of $3 \%$ meta-phosphoric acid in a blender and filtered through filter paper. An aliquot of filtrate containing $0.5 \mathrm{mg}$ of ascorbic acid was sampled, and mixed with citrate-phosphate buffer ( $\mathrm{pH} 3.6)$ to form buffered extract. The buffered extract was quickly mixed with indophenols solution and read absorption at $520 \mathrm{~nm}$ with 3\% meta-phosphoric acid as blank. A calibration standard curve of ascorbic acid was used to calculate the total ascorbic acid with a unit of milligrams of ascorbic acid per gram of freeze-dried amaranth (mg/g).

\subsection{Determination of Total Carotenoids}

Total carotenoids content was determined according to a previous publication (Song and $\mathrm{Xu}, 2013$ ). Briefly, the freeze-dried raw or processed amaranth (0.2 g) was extracted with $5 \mathrm{~mL}$ of acetone in a water bath at $50^{\circ} \mathrm{C}$ for $15 \mathrm{~min}$. The mixture was centrifuged at $4200 \mathrm{rpm}$ for 3 min. The supernatant was collected in $25 \mathrm{~mL}$ volumetric flask. The residue was extracted two more times with acetone under the same procedures. All the supernatants were collected in the $25 \mathrm{~mL}$ volumetric flask and bring to scale with acetone. $1 \mathrm{~mL}$ of extract was diluted by $9 \mathrm{~mL}$ acetone, and the total carotenoids were determined at 475 nm against the acetone blank.

\subsection{Determination of Lutein}

The lutein was determined using the method in the AOAC 43.018-43.023. Briefly, $0.2 \mathrm{~g}$ of freeze-dried edible amaranth was added into a $100 \mathrm{~mL}$ of volumetric flask with $1 \mathrm{~mL}$ distilled water and $30 \mathrm{~mL}$ of hexane, acetone, alcohol, methylbenzene (10:7:6:7). The sample was saponified with methanol and dilution with hexane.
Lutein and the phenyl (azo-1)-2-hydroxy beta (Sudan I ) working solution as a calibration factor was measured at $474 \mathrm{~nm}$.

\subsection{Determination of Beta-Carotene}

Beta-Carotene was determined according to Spirulina Pacifica Technical Bulletin \#003b of Cyanotech Corporation. Briefly, $0.2 \mathrm{~g}$ freeze-dried edible amaranth was extracted in a tube with $2.5 \mathrm{~mL}$ DMSO by vortex. The solution was extracted with methanol for four times by centrifugation and then diluted into $25 \mathrm{~mL}$ solution with methanol. Saponification was conducted with $8 \mathrm{~mL}$ of the methanol extract, $5 \mathrm{~mL}$ of heptane and $1.5 \mathrm{~mL}$ of saturated $\mathrm{KOH}$ solution in the dark. Heptane was used twice to extract the carotenoids from above mixture. The beta-carotene was determined at $436 \mathrm{~nm}$ against a heptane blank.

\subsection{Determination of Ferric-Reducing Antioxidant Power (FRAP)}

The FRAP assay was performed as the method described previously (Xu and Chang, 2007). The FRAP value was expressed as microgram of $\mathrm{Fe}^{2+}$ equivalent per $\mathrm{g}$ of freeze-dried amaranth $(\mu \mathrm{g} / \mathrm{g})$ using the calibration curve of $\mathrm{Fe}^{2+}$.

\subsection{Statistical Analysis}

The results were presented as the mean \pm standard deviation of three parallel measurements, and all statistical comparisons were made by means of ANOVA test and using SPSS software version 18 for windows (free version). It was considered as significantly different when $p<0.05$ determined by Duncan's Multiple Range Test.

\section{Result and Discussion}

\subsection{Effects of Home Cooking Manners on Polyphenol of Edible Amaranth}

Total phenolic content in the edible amaranth was shown in Table 1. Different home cooking had extremely significant $(p<0.001)$ effect on polyphenol content on a dry weight basis. The decreasing sequence of polyphenol was steamed $>$ raw $>$ blanched $>$ boiled $>$ simmered $>$ fried. Steaming process increased the polyphenol content about 50\%. The blanching, boiling and simmering method lowered the polyphenol content in the cooked amaranth, about $2.9 \%, 26.5 \%$, and $31.1 \%$, respectively. The frying caused a slight improvement $(0.1 \%)$ in the polyphenol content in edible amaranth. Adithya (2012) proved that the total phenolic content and antioxidant activity of all the extracts of raw amaranth was higher than that of its blanched counterparts. About $82 \%$ of phenolic compounds were lost into the cooking water, after the green vegetables had been blanched for $15 \mathrm{~min}$; the polyphenols had been broken down during cooking (Price et al., 1997). Therefore, the initial content of polyphenol was reduced by blanching, boiling and simmering. According to Chu et al. (2002), especially bound phenolics in total phenolics ranged from $20.5 \%$ in broccoli to $32.9 \%$ in cabbage. Bahorun (2004) reported that phenolics in vegetables also incurred in both free and conjugated forms. Generally, 
fresh vegetables contain only conjugated flavonoids, and heat treatment increased the level of free flavonols
(Stewart et al., 2000). This can explain why frying and steaming increased the amount of the polyphenol.

Table 1. Total polyphenol, anthocyanins, $L$-ascorbic acid, and FRAP of raw and processed edible amaranth

\begin{tabular}{ccccccc}
\hline Variables & Raw & Boiling & Steaming & Simmering & Frying & Blanching \\
\hline Total polyphenol $(\mathrm{mg} / \mathrm{g})$ & $1.94 \pm 0.04 \mathrm{~b}$ & $1.43 \pm 0.04 \mathrm{~d}$ & $2.96 \pm 0.02 \mathrm{a}$ & $1.34 \pm 0.03 \mathrm{e}$ & $1.94 \pm 0.03 \mathrm{~b}$ & $1.89 \pm 0.01 \mathrm{c}$ \\
\hline Anthocyanins $(\mu \mathrm{g} / \mathrm{g})$ & $50.9 \pm 0.82 \mathrm{a}$ & $44.8 \pm 0.24 \mathrm{c}$ & $46.1 \pm 0.48 \mathrm{~b}$ & $33.1 \pm 0.48 \mathrm{~d}$ & $6.15 \pm 0.08 \mathrm{f}$ & $26.4 \mathrm{e} \pm 0.55 \mathrm{e}$ \\
\hline$L$-ascorbic acid $(\mathrm{mg} / \mathrm{g})$ & $1.23 \pm 0.00 \mathrm{c}$ & $1.29 \pm 0.00 \mathrm{~b}$ & $1.49 \pm 0.01 \mathrm{a}$ & $1.00 \pm 0.01 \mathrm{f}$ & $1.02 \pm 0.01 \mathrm{e}$ & $1.06 \pm 0.00 \mathrm{~d}$ \\
\hline FRAP $(\mu \mathrm{g} / \mathrm{g})$ & $302.5 \pm 4.2 \mathrm{e}$ & $440.1 \pm 8.2 \mathrm{~d}$ & $1024.6 \pm 4.6 \mathrm{a}$ & $445.7 \pm 9.5 \mathrm{~cd}$ & $603.4 \pm 10.0 \mathrm{~b}$ & $454.0 \pm 5.5 \mathrm{c}$ \\
\hline
\end{tabular}

3.2. Effects of Home Cooking Manners on Anthocyanins of Edible Amaranth

Anthocyanins content in edible amaranth was shown in Table 1. Cooking had an extremely significant effect on total polyphenol $(p<0.001)$. After cooking procedures, the content of anthocyanins was decreased, especially by frying. It obviously that the anthocyanins content in the edible amaranth ranked in raw $>$ steamed $>$ boiled $>$ simmered $>$ blanched $>$ fried. $87.9 \%$ of its initial content was lost during frying in amaranth. Simmering determined a severe decrease of their initial concentration about $35.2 \%$ in amaranth, while the steaming and blanching caused a slight significant decrease $9.5 \%$ in anthocyanins content. Boiling reduced $12.1 \%$ of anthocyanins content in edible amaranth. According to Ahmed et al., (2010), 1.78 fold of anthocyanins of sweet potato declined after frying process, the sequence of anthocyanins was steamed > boiled $>$ fried, which exhibited an identical trend as a result of edible amaranth by above cooking manners. Ninfali et al. (2005) reported that red onion was considered as the source of the anthocyanins and the severity of the cooking treatment for red onion was frying > boiling, because frying created a high temperature to destroy the anthocyanins. Temperature increase will see greater degree destruction in anthocyanins due to the hydrolyzation of the free glycoside structure (Laleh, 2006). Maccarone et al. (1985) studied the stability of anthocyanins in red orange juice in 15, 25 and 35 degree $C$ during 15 day period storage and found that increase in temperature accelerated the destruction of anthocyanins.

\subsection{Effects of Home Cooking Manners on Vitamin C of Edible Amaranth}

Table 1 indicated the content of $L$-ascorbic acid in cooked amaranth. The raw edible amaranth contained vitamin C $1.23 \mathrm{mg} / \mathrm{g}$ on dry weight basis. Cooking had a significant $(p<0.01)$ effect on vitamin $C$. The reduction in vitamin $C$ content could be attributed to the fact that it was water soluble and thermal instability (Oboh et al., 2005). The $L$-ascorbic acid ranged from $1.00 \mathrm{mg} / \mathrm{g}$ to 1.49 $\mathrm{mg} / \mathrm{g}$ in amaranth. The descending order of the $L$-ascorbic acid in edible amaranth was steamed $>$ boiled $>$ raw $>$ fried $>$ simmered. Simmering, frying and blanching possessed a negative effect on the content of $L$-ascorbic acid $(-18.6 \%,-17.2 \%,-14.0 \%)$ in amaranth. Attributed to the fact that in the initial time of boiling during 5-10 min, the maximum amount of vitamin $\mathrm{C}$ was destroyed or leached into the water; hence there was a small amount left in the vegetables during the later boiling time (Agbemafle, 2012). The boiling time of simmering was longer than that of blanching and boiling, as a result of the most significant reduction of vitamin $\mathrm{C}$ by simmering. Frying had a negative effect (17.2\%) on vitamin $C$ content because the high temperature could destroy vitamin $\mathrm{C}$. The steaming increased the content of vitamin $C$ because of less vitamin $C$ release from the cell tissue of amaranth. Yadav et al. (1995) reported that ascorbic acid content of fresh leaves was 6.24 to $6.29 \mathrm{mg} / \mathrm{g}$ amaranth (Amaranthus tricolor). A marked reduction in $L$-ascorbic acid and $\beta$ carotene was observed in dried, blanched and cooked leaves.

\subsection{Effects of Home Cooking Manners on Carotenoids of Amaranth}

The total carotenoid contents of raw and processed amaranth were presented in Figure 2. The total carotenoids content in raw amaranth was $1.42 \mathrm{mg} / \mathrm{g}$. After cooking, total carotenoids content in amaranth was presented in descending order: blanched $>$ simmered $>$ boiled $>$ steamed $>$ fried $>$ raw amaranth (shown in Figure 2). There was a significant $(p<0.01)$ effect of cooking on the content of total carotenoids in the edible amaranth, thus heating significantly increased the content of carotenoids. The total carotenoids contents in blanched, boiled and simmered amaranth were increased by $142.3 \%, 111.4 \%$, and $111.3 \%$, respectively. Khachik et al. (2008) found that boiling and frying manners promoted the content of carotenoids compared to the raw one. The reason was that the hydrophilic compound lost in the water whereas the hydrophobic compounds were released from the tissue of the tomato. For frying, the heating facilitated the carotenoids dissolved in the oil resulting in increasing the carotenoids content. Cooking of green fresh vegetables had been reported to promote the release of carotenoids from the matrix because of the disruption of carotenoidprotein complexes, leading to better extractability and high concentrations in cooked samples. The contents of all carotenoid compounds significantly increased in boiled and steamed broccoli (32\% and 19\%, respectively) in comparison to the raw ones. Conversely, frying determined a $67 \%$ loss of the initial carotenoid concentration, probably because of leaching of lipophilic compounds into oil and degradation by higher processing temperature (Miglio et al., 2008).

Contents of lutein in raw and processed amaranth were presented in Figure 2. The lutein content in raw amaranth was $1.25 \mathrm{mg} / \mathrm{g}$. The lutein content in amaranth presented in a descending order: blanched $>$ simmered $>$ steamed $>$ boiled $>$ raw $>$ fried. Blanching and simmering promoted the content of lutein. The blanching, simmering, steaming and boiling had a positive effect on the concentration of lutein, but frying reduced lutein content by $52.1 \%$. The results are identical with the literature in which lutein content was increased from $168 \%-419 \%$ for red spinach 
(Amaranth gangenticus) by thermal processing. This showed a good stability of lutein during boiling (Aman, 2005). Hart and Scott (1995) demonstrated that boiled spinach comprise of higher lutein content than the raw ones. Miglio et al. (2008) reported that the lutein was lost by frying, and it has the same tendency as the current study. As a lipophilic compound, lutein was dissolved in heating oil, and then lost from the vegetables.

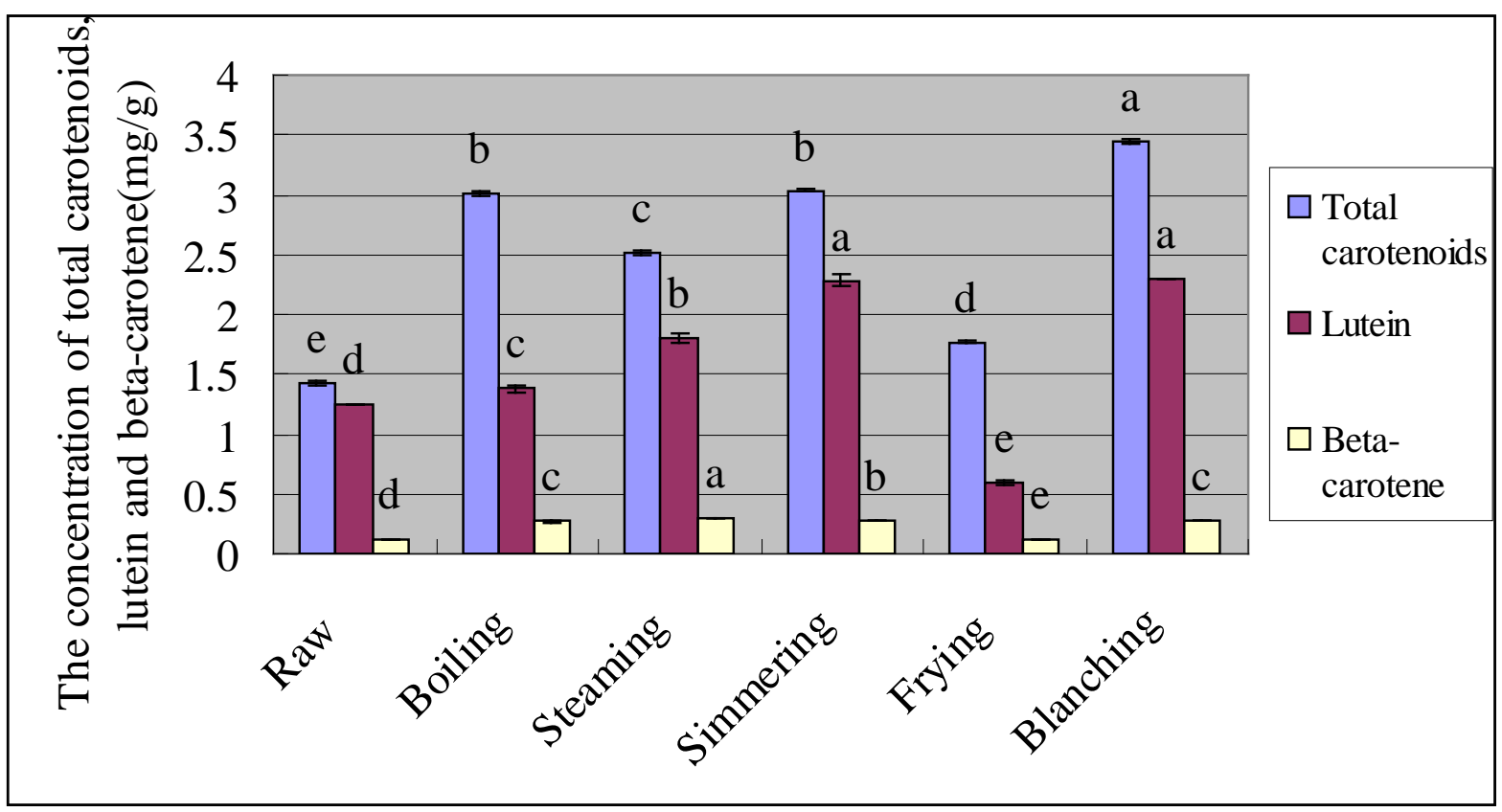

Figure 2. Total carotenoids, lutein and beta-carotene contents of raw and processed amaranth

The contents of the beta-carotene in raw and processed amaranth were shown in Figure 2. The beta-carotene in raw amaranth was $123.1 \mu \mathrm{g} / \mathrm{g}$, the steamed amaranth presented the highest beta-carotene content $(300.2 \mu \mathrm{g} / \mathrm{g})$. Approximate one fold increases in the beta carotene for boiled, steamed, simmered, and blanched amaranth. There were extremely significant increase in the beta carotene by the thermal treatment, such as boiling, steaming, blanching, simmering $(p<0.01)$, but it had less significance effect by frying process $(0.01<p<0.05)$. The steaming method had most positive effect on increasing the beta carotene content. Frying had a slight effect in decreasing the $\beta$-carotene $(-9.4 \%)$ and moderate effect on lutein $(-52.1 \%)$, but increased total carotenoids content. It was reported that both lutein and $\beta$-carotene were lost by frying. In conclusion, $\beta$-carotene had a higher thermal stability than lutein. Thus, more extractable $\beta$ carotene released through cell wall disruption in the case of suitable time and temperature (Miglio et al., 2008).

\subsection{Effect of Home Cooking Manners on Antioxidant Activities of Edible Amaranth}

The various FRAP values of raw and processed amaranth were shown in Table 1. The home cooking manners improved the FRAP values of amaranth from $302.5 \mu \mathrm{gFE} / \mathrm{g}$ to $1024.6 \mu \mathrm{g} \mathrm{FE} / \mathrm{g}$. The decreasing order of the FRAP value was steamed $>$ fried $>$ blanched $>$ simmered $>$ boiled $>$ raw amaranth. The FRAP values were affected mostly by steaming, while above one over three fold increases of the initial value of FRAP were found in boiled, simmered and blanched amaranth. The improvement of antioxidant activities was found in the processed amaranth because the antioxidant components, such as total polyphenol, $L$-ascorbic acid, total carotenoids, lutein and beta-carotene were all increased except for anthocyanins. Gundgaard et al. (2003) concluded that boiling improved the FRAP level of all the vegetables as compared to the raw vegetable extracts. It was reported that total antioxidant activities of pepper, green beans, broccoli and spinach significantly $(p<0.05)$ were increased during cooking as compared to the values of the fresh ones (Gazzani et al., 1998). The steaming increased most of the nutrition such as vitamin $\mathrm{C}$, beta-carotene, polyphenol, on the contrary the simmering destroyed most of the bioactive components.

\section{Conclusions}

Edible amaranth vegetable was consumed after home cooking such as boiling, frying, simmering, blanching and steaming. The health beneficial antioxidant activities are related to their bioactive components. Cooking had no deleterious effect on total bioactive component except for the reduction of anthocyanins content, but home cooking increase the antioxidant activities and the contents of carotenoids, especially by steaming. Steaming had a positive effect on the polyphenol, $L$-ascorbic acid, which lost seriously after simmering procedure. Both simmering and blanching increased the beta carotene and lutein in the cooked amaranth.

\section{Acknowledgement}

This research was jointly supported by Natural Science Foundation of Guangdong Province, China (Project code: S2012010008961), and a research grant (UICRG 201329) from Beijing Normal University-Hong Kong Baptist University United International College, China. 


\section{References}

[1] Agbemafle, R., Edward, A. O., Genevive, E. A., \& Daniel, N. A. (2012). Effects of boiling time on the concentrations of vitamin c and beta-carotene in five selected green vegetables consumed in Ghana. Applied Science Research, 3, 2815-2820.

[2] Ahmed, M., Sorifa, A. M., \& Eun, J. B. (2010). Effect of pretreatments and drying temperatures on sweet potato. International Journal Food Science and Technology 45, 726-732.

[3] Adithya, S. E., Lakshmi, M. S., Krishnakumar, K. A., \& Christabel1, P. H. (1998). A study on the effect of blanching on phenolic content and antioxidant activity of Amaranthus tricolor L. leaf and stem. Free Radical Biology and Medicine, 25(1), 113-120.

[4] Aman, R., Schieber, A., \& Carle, R. (2005). Effects of heating and illumination on trans-cis isomerization and degradation of $\beta$ carotene and lutein in isolated spinach chloroplasts. Journal of Agricultural and Food Chemistry, 53, 9512-9518.

[5] Bahorun, T., Luximon-Ramma, A., Crozier, A., \& Aruoma, O. I. (2004). Total phenol, flavonoid, proanthocyanidin and vitamin C levels and antioxidant activities of Mauritian vegetables. Journal of the Science of Food and Agriculture, 84, 1553-1561.

[6] Bernhardt, S., \& Schlich, E. (2006). Impact of different cooking methods on food quality: Retention of lipophilic vitamins in fresh and frozen vegetables. Journal of Food Engineering, 77, 327-333.

[7] Chen, B. H., Peng, H. Y., \& Chen, H. E. (1995). Changes of carotenoids, color and vitamin A contents during processing of carrot juice. Journal of Agricultural and Food Chemistry, 43, 1912-1918.

[8] Chu, Y. F., Sun, J., Wu, X., \& Liu, R. H. (2002). Antioxidant and antiproliferative activities of common vegetables. Journal of Agricultural and Food Chemistry, 50, 6910-6916.

[9] Edelstein, S., \& Sharlin, J. (2009). Life cycle nutrition. ISBN-13: 978-0-7637-3810-5g. Jones and Bartlett Publishers. Aging theory P381-382.

[10] Gundgaard, J., Nielsen, J. N., Olsen, J., \& Sorensen, J. (2003). Increased intake of fruit and vegetables: Estimation of impact in terms of life expectancy and healthcare costs. Public Health Nutrition, 6, 25-30.

[11] Gazzani, G., Papetti, A., Massolini, G., \& Daglia, M. (1998). Antiand prooxidant activity of water soluble components of some common diet vegetables and the effect of thermal treatment. Journal of Agricultural and Food Chemistry, 46, 4118-4122.

[12] Hart, D. J., \& Scott, K. J. (1995). Development and evaluation of an HPLC method for the analysis of carotenoids in foods and measurement of the carotenoid content of vegetables and fruits commonly consumed in the UK. Food Chemistry, 54, 101-111.

[13] Huang, X. Y., Cai, W. X., \& Xu, B. J. (2014). Kinetic changes of nutrients and antioxidant capacities of germinated soybean (Glycine $\max$ L.) and mung bean (Vigna radiata L.) with germination time. Food Chemistry, 143, 268-276.

[14] Kalogeropoulos, N., Chiou, A., Mylona, A., Ioannou, M. S., \& Andrikopoulos, N. K. (2007). Recovery and distribution of natural antioxidants (alpha-tocopherol, polyphenols and terpenic acids) after pan-frying of Mediterranean finfish in olive oil. Food Chemistry, 100, 509-517.

[15] Khachik, F., Mudlagiri, B. G., Gary, R. B., Joanne, H., William, R., Lusby, M. D. T., \& Mercedes, R. B. (1992). Effect of food preparation on qualitative and quantitative distribution of major carotenoid constituents of tomatoes and several green vegetables. Journal of Agricultural and Food Chemistry, 40, 390-398.

[16] Kidmose, U., Yang, R. Y., Thislted, S. H., Christensen, L. P., \& Brandt, K. (2006). Content of carotenoids in commonly consumed Asian vegetables and stability and extractability during frying. Journal of Food Composition and Analysis, 19, 562-571.

[17] Kirthkar, K. R., \& Basu, B. D., (1987). Indian Medicinal Plants. Vol.3, 2nd ed. Dehra Dun: International Book Distributors, India, pp 2061-2062.

[18] Kumpulainen, J. T., \& Salonen, J. T. (1999). Natural antioxidants and anticarcinogens in nutrition, health and disease. ISBN: 978-185573-793-8. Woodhead Publishing.

[19] Laleh, G. H., Frydoonfar, H., Heidary, R., Jameei, R, \& Zare, S. (2006). The effect of light, temperature, $\mathrm{pH}$ and species on stability of anthocyanin pigments in four Berberis species. Pak Journal of Nutrition, 5, 90-92.

[20] Lakshmanb, K., Ashok Kumara, B. S., Jayaveeac, K. N., Sheshadri, S. D., Saleemulla, K., Thipperswamy, B. S., \& Veeresh, V. (2012). Antidiabetic, antihyperlipidemic and antioxidant activities of methanolic extract of Amranthus virid Linn. in alloxan induce diabetic rats. Experimental and Toxicological Pathology, 64, 75-79.

[21] Liu, R. D., Zhang, M., \& Li, X. X. (2008). Comparisons of extraction solvents and quantitative-methods for analysis of anthocyanins in strawberry and blueberry fruits. Acta Horticulturae Sinica, 35, 655-660

[22] Maccarone, E. A., Maccarone, P. R., \& Apisared. (1985). Stabilization of anthocyanins of blood orange fruit juice. Journal of Food Science, 50, 901-904.

[23] Madhav, C. K., Sivaji, K., \& Tulasi, R. K. Flowering Plants of Chitoor District, First edition, Tirupati, India: Students offset printers. 2008; pp. 291

[24] Melvin, H. W. (2010). Nutrition for health, fitness and sport. ISBN: 978-0-07 - 122001-9 published by Mc Graw-Hill P284.

[25] Miglio, C., Chiavaro, E., Visconti, A., Fogliano, V., \& Pellegrini, N. (2008). Effects of different cooking methods on nutritional and physicochemical characteristics of selected vegetables. Journal of Agricultural and Food Chemistry, 56, 139-147.

[26] Nilsson, J., Stegmark, R., \& Akesson, B. (2004). Total antioxidant capacity in different pea (Pisum sativum) varieties blanching and freezing. Food Chemistry, 86, 501-507.

[27] Ninfali, P., Mea, G., Giorgini, S., Rocchi, M., \& Bacchiocca, M. (2005). Antioxidant capacity of vegetables, spices and dressings relevant to nutrition. The British Journal of Nutrition, 93, 257-266.

[28] Oboh, G., Ekperigin, M. M., \& Kazeem, M. I. (2005). Nutritional and haemolytic properties of eggplant (Solanum macrocarpno) leaves. Journal of Food Composition and Analysis, 18, 153-160.

[29] Price, K. R., Bacon, J. R., \& Rhodes, M. J. C. (1997). Effect of storage and domestic processing on the content and composition of flavonols glucosides in onion (Allium cepa). Journal of Agricultural and Food Chemistry, 45, 938-942.

[30] Song, Y., \& Xu, B. J. (2013). Diffusion profiles of health beneficial components from goji berry (Lyceum barbarum) marinated in alcohol and their antioxidant capacities as affected by alcohol concentration and steeping time. Foods, 2, 32-42.

[31] Stewart, A. J., Bozonnet, S., Mullen, W., Jenkins, G. I., Michael, E. J., \& Crozier, A. (2000). Occurrence of flavonols in tomatoes and tomato-based products. Journal of Agricultural and Food Chemistry, 48, 2663-2669.

[32] Svobadova, A., Psotova, J., Walterova, D. (2003). Natural phenolics in the prevention of UV-induced skin damage. A review. Biomedical Papers, 147(2), 137-145.

[33] Thomas, S. C. (2008). Vegetable and fruits nutrition and therapeutic values. ISBN: 1-4200-b871-7. CRC press. Nutritional and therapeutic values of vegetables $\mathrm{P} 40$.

[34] Turkmen, N., Sari, F., \& Velioglu, Y. S. (2005). The effect of cooking methods on total phenolics and antioxidant activity of selected green vegetables. Food Chemistry, 93 713-718.

[35] Wallace, T. C. (2011). Anthocyanins in cardiovascular disease. Advances in Nutrition, 2, 1-7.

[36] Walter, C. W. (2001). Eat, drink, and be healthy. ISBN-13:978-07432-6642-0. Free Press. Eat plenty of fruits and vegetables P132.

[37] Wayne, R. B., Stanley, T. O., Mark, S. M., Debra, K. W., \& Topham. (2000). Phytochemicals as bioactive agents. ISBN: L5bb7b-788-L. CRC Press.

[38] Xu, B. J., \& Chang, S. K. C. (2007). A comparative study on phenolic profiles and antioxidant activities of legumes as affected by extraction solvents. Journal of Food Science, 72, 5159-5166.

[39] Xu, B. J., \& Chang. (2009). Total phenolic, phenolic acid, anthocyanin, flavan-3-ol, and flavonol profiles and antioxidant properties of pinto and black beans (Phaseolus vulgaris L.) as affected by thermal processing. Journal of Agricultural and Food Chemistry, 57, 4754-4764.

[40] Yadav, S. K., \& Sehgal, S. (1995). Effect of home processing on ascorbic acid and $\beta$-carotene content of spinach (Spinacia oleracia) and amaranth (Amaranthus tricolor) leaves. Plant Foods for Human Nutrition, 47, 125-131. 